\title{
Neologism in News English
}

\author{
ZHOU Li-na \\ China Youth University of Political Studies, Beijing, China
}

\begin{abstract}
Neologism is an important part of News English whose analysis and studying is of great significance to English learning. It covers a wide range of topics varying from politics, economy, culture, war, science, and technology, with diverse genres ranging from news story, editorial to features, and review. This paper discusses the formation of neologisms in News English: abbreviation, compounding, derivation, loan words, analogy, and meaning transfer in the context of English news with the aim of facilitating language learners in learning English and better understanding world news as well as cultivating their cross cultural communication ability.
\end{abstract}

Keywords: News English, neologisms, formation

\section{Neologism and News English}

News English covers a variety of topics: politics, economy, culture, war, science, and technology, with diverse genres ranging from news story, editorial to features, and review. It reports the latest news in modern English language. According to Webster's New World Dictionary, neologism is: a new word or a new meaning for an established word; the use of, or the practice of creating, new words or new meanings for established words. In order to gain an insight into the development of modern English, it is very important to study news English whose usage is closely connected with changes and development of neologism. Neologisms keep appearing and a better understanding of them helps learners command English language, gain necessary information, and cultivate their cross cultural communication ability. This paper mainly studies formation of neologisms in order to give learners a deeper insight into neologism in News English.

\section{Formation of Neologism in News English}

With the fast development of science, technology, and economy, new concepts and things come into being, making it hard to describe and reflect new changes. It is in this context that new words are created in News English and spread far and wide. However, no matter how great the changes are, formation of neologisms in News English conforms to the traditional rules of word formation. They are abbreviation, compounding, derivation, loan words, analogy, and meaning transfer.

\begin{abstract}
Abbreviation
Research shows readers of English news have an average of 3,000 to 5,000 vocabularies in the United States, most of whom are just ordinary people. All that they need is to get a quick glimpse of the brief news. For this
\end{abstract}

ZHOU Li-na, associate professor, master, Department of English Language and Literature, China Youth University of Political Studies. 
purpose, News English employs simple words to make the news more understandable and time saving. In addition, the authors of the News English have to make their report short and brief due to the limit of space. Short and small as they are, those words can express meanings clearly and at the same time attract people's attention.

Abbreviation is a shortened form of a word or phrase. It consists of a group of letters taken from the word or phrase. In order to save space, writers apply abbreviation in the process of news writing and it has become a trend in news writing resulting in more and more abbreviated neologisms. Abbreviated neologism in news writing can be categorized into three types: acronym, clipping, and blending.

Acronym. Acronym is kind of abbreviation used as a word which is formed from the initial components in a phrase or a word. Acronyms are more space saving, eye-catching, and interesting than the completed group of words. It is often used to abbreviate long and frequently referenced names of organizations such as AIIB (Asian Infrastructure Investment Bank) and WTO (World Tourism Organization). The public employ it in their daily social and cultural life. DINS (double income no sex), Kippers (kids in parents' pockets eroding retirement savings), and DWY (driving while yakking) are all the examples of acronyms, to name just a few. Business and industry also are prolific coiners of acronyms. Examples include B2B (business to business), CFO (chief financial officer), BAM (bric and mortar), and BRICs (Brazil, Russia, India, and China). The rapid development of science and technology is another driving force in its usage, since new inventions and concepts demand shorter neologisms. Examples are, TMT (technology, media, telecommunications), UMPC (ultra mobile personal computer), and VBIED (vehicle-borne improvised explosive device), etc.

Clipping. Clipping is the word formation process which consists in the reduction of a word to one of its parts. The most common type is apocope in which the beginning of the prototype is retained. Examples are: Decaf (decaffeinated), vert (vertical), techie (technician), and sig (signature). Final clipping or apheresis retains the final part of the prototype. Examples include: coon (raccoon), varsity (university), and net (Internet). Syncope is the word with the middle part of it left out: maths (mathematics) and specs (spectacles).

Blends. Blends combine lexemes to form a new word. For example, Chindia is a blend of China and India, Obamacon a blend of Obama and conservative, celeblog a blend of celebrity and blog, groceraunt a blend of grocer and restaurant, vegelate a blend of vegetable and chocolate, and e-lancer economy a blend of electronic, freelancer, and economy.

\section{Loan Words}

Loan word is a word borrowed from a source language and incorporated into a recipient language without translation. English is a mixture of various languages including French, Chinese, German, Italian, Greek, Russian, Japanese and Arabian, etc., since immigrants come from all over the world.

According to surveys, the percentage of modern English words derived from each language is $29 \%$ from French, 29\% from Latin, 26\% from German, 6\% from Greek, the rest accounting for 6\%. News English often reports world news and loan word use cannot only attract the readers' attention but provide them with direct foreign information. Words of Chinese origin have entered the English language, most of which were loanwords from Chinese itself and some of which have also entered indirectly via other languages such as Japanese and Korean. For example, taikonaut, wirefu, tuhao, dama, wechat, and fengshui, etc. Loan words from Japanese are 
tsunami, manga, ciabatta, and aitech. Italian loan words include trattoria, bimbo, paparazzi, and snaparazzi. French new loan words include déjà vu, jamai vu, déjà dit, franc fort, touché, parkour, etc. Loan words from Indian are bangle, guru, and lulu; From German are Ossi doktorvater, Professoriat, gemutlich, kaffeeklatsch, kaput, kitsch,waldsterben; From Russian are pamyat, lasik and intelligentsia, glasnost, Lunokhod, Lunik, Politburo, sputnik, icon muzhik; From Spanish are plaza, silo, bonanza, salsa, fiesta, etc. The loan words from those languages make English colorful, expressive, and productive.

\section{Compounding}

A compound is a word composed of more than one free morpheme. It is the process of word formation that creates compound lexemes. This type of formation has the largest number and is increasing. The component stems of a compound may be categorized into several major types: noun, verb, and adjective. Examples are cable ready, acid jazz, bubble tea, latte factor, universal release, economic downturn, pink slip party, office spouse, quiet date, power nap, trophy wife, hockey mom, Alpha mom, unwedding ceremony, speed date, shutter man, sit-in; cut and shut, writeprint, green wash, freeze dry, take out, highlight, offset, cross-question, dog sit; blue green, fat free; make under, over ripe, value-added, epoch-making, export-oriented, overseas-funded, clean limbed, car schooling, fast-fingered, and newly-published.

\section{Derivation}

Derivation is the forming of a new word based on an existing word. It often involves the addition of a morpheme in the form of an affix, such as suffix -ness, -tion, and prefix un-, dis-, etc. With the peaceful rising of China, It is playing a greater role in international politics, culture, and economy. Neologisms beginning with prefix Chi- appear and have become a hot word: Chinology, Chimerica, Chindia, Chimerny, and Chinglish. Neologisms with suffix - vore appear recently in large numbers: oppotunivore, vegivore, locavore, faunavore, photovore, planktivore, and piscivore. More examples are canyoning, unturkey, bootable, Floridization, worklessness, incubator, demall, supersize, trashy, dejunk, regift, and deshopping.

Derivation can also occur without any change of form but part of speech, for example, friend (noun) and to friend. This is called conversion, or zero derivation. More examples are lance (noun) and to lance, dump (verb) and a dump, commute (verb) and a commute to London, green (adjective) and to green, priviledged (adjective) and the priviledged (noun), underpriviledged (adjective) and the underpriviledged.

\section{Analogy}

Analogy is a cognitive process of transferring information or meaning from a particular source to another target, or a linguistic expression corresponding to such a process. Neologisms can be formed by analogy with existing words. Example are: beerholic, colaholic, movie-holic, teleholic, carboholic, loveholic, milkhaulic, and surgiholic are formed by analogy with workaholic. Other analogous neologisms are color analogy including grey collar, pink-collar, new collar, gold collar, bright collar, green collar, and black collar from white collar; number analogy 3I's (inflation, interest rate, and impeachment) from 3R's (reading, writing, and arithmetic); antonym analogy brain gain is shaped from brain drain, down market from upmarket, sit tragedy from sitcom; place analogy such as cityscape, moonscape, netscape, riverscape, roofscape, waterscape, seascape, streetscape from landscape, etc. As a result, neologism formed by analogy abound in large number. 


\section{Meaning Transfer}

With development of science and technology and progress of society, new concepts come into being requiring neologisms to put them into vivid and clear expression. However, new concepts do not necessarily need creation of new words. Instead they can be conveyed by meaning transfer. "Bail out" came from French baille, meaning bucket and jumping out of the plane. However, with the passage of time, people now use it to mean giving financial support to those in trouble and get them out of it. For example, Salt Lake Tribune reported that President Obama said the government will recover all the taxpayer money his administration provided to bail out the auto industry last year. In an interview aired Thursday on the ABC daytime talk show "the View", Obama said the auto industry "tells a good story" of his administration efforts to rescue the economy. More examples would be: hoodie transfering meaning from clothes to cynical young people, size zero from zero to skinny model, lame from crippled to bad, and beat from verb hit to adjective ugly.

\section{Conclusion}

English news has become an important part of English learning in which neologism with its diverse sources and concise formation, provides special corpus for English research. Neologism not only promotes the development of news English and English but also reflects culture and society. Knowledge of the features of neologisms in News English not only enables learners to better understand the formation of English words, world news but also cultivates their cross cultural communication ability.

\section{References}

Agnes, M. E. (2003). Webster's new world dictionary. New York: Simon \& Schuster.

LI, P. W. (2014). English roots and how to use them to decipher their derivatives. Fujiang: Fujiang Publishing House. Oxford English dictionary. (2011). Oxford: Oxford University Press.

ZHANG, J. (2004). Jounalistic English: Style and analysis. Shanghai: Shanghai Foreign Language Education Press. 